\title{
A comparison of long-term efficacy of K-rod- assisted non-fusion operation and posterior lumbar interbody fusion for single-segmental lumbar disc herniation
}

\section{Xueliang Cheng}

Jilin University Second Hospital

Yang Qu

Jilin University Second Hospital

Rongpeng Dong

Jilin University Second Hospital

Mingyang Kang

Jilin University Second Hospital

Jianwu Zhao ( $\sim$ jianwu@jlu.edu.cn )

Jilin University Second Hospital https://orcid.org/0000-0003-0574-9742

\section{Research article}

Keywords: Lumbar disc herniation, K-rod, Posterior lumbar interbody fusion, Adjacent segment degeneration, Spino-pelvic parameters, Non-fusion

Posted Date: March 3rd, 2021

DOl: https://doi.org/10.21203/rs.3.rs-273166/v1

License: (c) (1) This work is licensed under a Creative Commons Attribution 4.0 International License. Read Full License

Version of Record: A version of this preprint was published at Journal of Clinical Neuroscience on January 1st, 2022. See the published version at https://doi.org/10.1016/j.jocn.2021.11.025. 


\section{Abstract}

\section{BACKGROUND}

Since the development of internal fixation, posterior lumbar interbody fusion (PLIF) surgery has become the gold standard for the treatment of lumbar disc herniation. Although it has good short-term clinical efficacy, it can result in problems such as postoperative intractable lower back pain and degeneration of adjacent segments. K-rod-assisted non-fusion surgery for the treatment of lumbar disc herniation has also been proven to have clinical efficacy; however, its long-term effects have not been examined.

AIM

To compare the long-term clinical efficacy of K-rod-assisted non-fusion operation to the clinical efficacy of PLIF in the management of single-segment lumbar disc herniation.

\section{METHODS}

This study retrospectively analyzed 22 patients with lumbar disc (L4/5) herniation who underwent K-rodassisted non-fusion operation ( $n=13)$ or PLIF $(n=9)$ between December 2010 and December 2013 and were followed-up for more than 5 years. Clinical outcomes were evaluated by the Oswestry Disability Index (ODI), pain Visual Analogue Score (VAS), and Japanese Orthopaedic Association Back Pain Evaluation Questionnaire (JOABPEQ). Imaging evaluations included adjacent segmental intervertebral height, range of motion (ROM) of the vertebrae, incidence of lumbar instability, spino-pelvic parameters, Pfirrmann grading, Modic changes, and University of California Los Angeles (UCLA) grading.

\section{RESULTS}

Clinical outcomes, namely operation times $(110.5 \pm 11.15 \mathrm{~min}$ vs. $134.44 \pm 12.36 \mathrm{~min}, P<0.05)$ and blood loss $(59.2 \pm 7.03 \mathrm{ml}$ vs. $80.0 \pm 8.66 \mathrm{ml}, P<0.05)$, were significantly reduced in the K-rod group compared to the PLIF group. At the last follow-up, the clinical outcomes of the K-rod group were improved compared to those of the PLIF group as observed by the VAS score ( $2.1 \pm 0.9$ vs. $3.0 \pm 0.7, P<0.05)$, JOABPEQ $(26.7 \pm 1.1$ vs. $25.2 \pm 1.5, P<0.05)$, and ODI $(21.0 \pm 3.7$ vs. $28.4 \pm 6.9, P<0.05)$. Imaging outcomes at the last follow-up indicated that the loss of height in the $L 3 / 4$ intervertebral space $(0.4 \pm 0.9 \mathrm{~mm}$ vs. $1.5 \pm 0.7 \mathrm{~mm}, P<0.05)$ and L5/S1 intervertebral space $(0.2 \pm 0.5 \mathrm{~mm}$ vs. $1.8 \pm 1.7 \mathrm{~mm}, P<0.05)$, the ROM of L3/4 (4.9 \pm 2.0 vs. 8.8 $\pm 2.4, P<0.05)$, the ROM of L5/S1 (5.7 \pm 1.7 vs. $8.6 \pm 1.2, P<0.05)$, and the incidence of adjacent segment degeneration $(7.7 \%$ vs. $38.9 \%, P<0.05)$ in the PLIF group were significantly higher than those in the K-rod group. According to Pfirrmann grading, Modic changes, and UCLA grading, the incidence of adjacent segment degeneration was $55.6 \%$ in the PLIF group and $15.4 \%$ in the K-rod group. Changes in spino-pelvic parameters between the two groups were as follows: pelvic index remained unchanged, pelvic tilt angle increased, and lumbar lordosis and sacral slope decreased. 
Compared to PLIF, single-segment lumbar disc herniation using K-rod-assisted non-fusion surgery resulted in better long-term clinical efficacy. Our results demonstrate that this procedure can delay adjacent segment degeneration after lumbar surgery.

\section{Introduction}

Although posterior lumbar interbody fusion (PLIF) has gradually become the "gold standard" for the surgical treatment of degenerative diseases of the spine, complications such as adjacent segment degeneration (ASD) ${ }^{1}$ and postoperative low-back pain, ${ }^{2}$ affect the long-term clinical efficacy of the operation. A previous study observed that the incidence of complications identified through symptomatology was $5-20 \%$, while the incidence of complications identified through imaging studies was $8-100 \%{ }^{3-6}$ The reason for such a wide range of incidences among imaging studies may be the differing diagnostic criteria for degeneration observed by imaging. Imagama et al. ${ }^{7}$ and lorio et al., ${ }^{8}$ found that the main cause of degeneration after lumbar surgery was not age, but changes in spinal mechanics caused by lumbar surgery and internal fixation. Therefore, to prevent the degeneration of adjacent segments after spinal surgery, choosing an optimal surgical method and internal fixation device is highly important. Dynamic fixation has been proposed as a potential method, and it aims to prevent lumbar instability, intractable low-back pain, and ASD ${ }^{9--11}$ by partially restricting movement or load. Dynamic fixation seeks to preserve normal lumbar activity and to reduce abnormal activity. The K-rod system (which stands for K-rod system-assisted elastic internal fixation) is another surgical modality for the management of degenerative diseases of the spine, such as disc herniation. The short-term clinical efficacy of the K-rod system in the treatment of lumbar degenerative diseases has been confirmed, ${ }^{12-14}$ but there are few reports examining its long-term clinical efficacy. Furthermore, considering that ASD occurs approximately 2 years after lumbar surgery and the incidence of ASD increases at a rate of approximately $3 \%$ per year, ${ }^{1,3}$ it is necessary to explore the long-term clinical efficacy of surgical treatment methods for degenerative diseases of the spine. This study aimed to compare the clinical outcomes of K-rod-assisted non-fusion surgery and those of PLIF for the treatment of lumbar disc herniation and the roles of these procedures in delaying the degeneration of adjacent spinal segments.

\section{Materials And Methods}

\section{General data}

This study retrospectively analyzed the clinical data of patients who had lumbar disc herniation and underwent surgical treatment between December 2010 and December 2013; the study participants were followed-up for more than 5 years.

Patients who met the following criteria were included in the study: (1) patients less than 55 years of age, (2) patients who had a single lumbar disc herniation (L4/5) and whose symptoms were not significantly 
alleviated after conservative treatment for more than 3 months, and (3) patients who underwent K-rod system-assisted non-fusion surgery or PLIF for the treatment of disc herniation.

Patients with any of the following criteria were excluded from the study: (1) patients with complications of other diseases of the spine, such as inflammatory disease, infections, rheumatism, fractures, and immune system diseases, (2) patients with a history of spine surgery and trauma, (3) patients who had undergone internal fixator removal, and (4) patients with incomplete clinical data, (5) age greater than 55 years.

Based on the above criteria, 13 and 9 cases were included in the K-rod and PLIF groups, respectively.

\section{Surgical method}

K-rod group: After administering general anesthesia, the patient was placed in a prone position and support paddings were used to lift the abdomen in order to fully increase the intervertebral spaces. A digital radiography machine was used to locate the segment to be operated, and the segment was well marked. The skin over the identified segment was then disinfected, and sterile, single-use instruments were employed. Incisions measuring approximately $7 \mathrm{~cm}$ in length were made along the posterior midline of the lower back to expose the lamina and articular process. Pedicle screws were implanted while carefully retaining the posterior column ligament complex, including the supraspinal ligament. An appropriate length of elastic K-rod and polyetheretherketone shells were used, and the screw cap was tightened. Decompression was performed at the L $4 / 5$ level by fenestration to expose the dural sac. After stripping and protecting the nerve root, the position of the protruding disc was defined. The posterior longitudinal ligament was then cut with a sharp knife, and nucleus pulposus forceps were used to remove the free nucleus pulposus tissue and broken disc tissue. Bipolar electrocoagulation was used to control bleeding. The nerve root passage was explored, and the tension at the nerve root was palpated. After confirming that there was no obvious nerve root entrapment, the incision was fully washed with saline, and the lamina window was covered with a gelatin sponge. An indwelling drainage tube was then fixed and free drainage through the tube was ensured after layer-by-layer suturing of the surgical incision.

PLIF group: The procedure for PLIF was similar to that of K-rod insertion, except that a rigid titanium rod was used instead of a K-rod. The spinous process and the lamina of the L4 vertebrae were also removed. After discectomy, the upper and lower endplates were scraped with a curette. Autogenous bone or allogeneic artificial bone was then implanted into the intervertebral space.

All the surgeries in this study were performed by the same surgical team.

The patients were treated with dehydration, anti-inflammatory drugs, antibiotics, nerve nutrition, etc. When the surgical site drainage volume was $<50 \mathrm{~mL}$ over $24 \mathrm{~h}$, the drainage tube was removed. Patients who underwent K-rod surgery were allowed to walk with thoracolumbar brace one week after surgery. Patients who underwent PLIF, were recommended to walk 3 weeks after the operation. All patients performed active muscle exercises during bed rest and were advised to wear thoracolumbar brace when walking within 3 months after surgery. 


\section{Measures}

The following clinical measures were used: pain Visual Analogue Scale (VAS), Oswestry Disability Index (ODI), and Japanese Orthopaedic Association Back Pain Evaluation Questionnaire (JOABPEQ). The following imaging measures were used: height of the intervertebral space $(\mathrm{H})$, intervertebral range of motion (ROM), lumbar lordosis (LL) angle, pelvic tilt (PT) angle, sacral slope (SS), pelvic index (PI), incidence of lumbar instability, University of California, Los Angeles (UCLA) classification of intervertebral space degeneration on X-ray, Pfirrmann classification of lumbosacral disc degeneration, and Modic classification of changes in the vertebrae on magnetic resonance imaging (MRI). The methods used to measure $\mathrm{H}^{15}$ and spino-pelvic parameters are shown in Figs. 1 and 2 .

\section{Statistical analysis}

All data were analyzed with SPSS version 22.0 software. All mean values were expressed as mean \pm SD. Student's $t$ test was used to compare the differences between intragroup variables and intergroup variables. Chi-square test $\left(\chi^{2}\right)$ was used for the comparison of two rates. A $P$-value of $<0.05$ was considered statistically significant.

\section{Results}

\section{Demographic data}

The clinical data of 22 patients were used in the study (K-rod group, $n=13$; PLIF group, $n=9$ ). There were no significant differences between the two groups in demographic characteristics, such as age, sex, body mass index, and follow-up duration (Table 1). Operative times (110.5 $\pm 11.15 \mathrm{~min}$ vs. $134.44 \pm 12.36 \mathrm{~min}$, $P<0.05)$ and blood loss $(59.2 \pm 7.03 \mathrm{ml} v \mathrm{ss} .80 .0 \pm 8.66 \mathrm{ml}, P<0.05)$ were significantly reduced in the K-rod group compared to the PLIF group (Table 1). 
Table 1

Demographic data of the patients in two groups

\begin{tabular}{|lllc|}
\hline & K-rod group & PLIF group & $P$ value \\
\hline Sex(M/F) & $(6 / 7)$ & $(4 / 5)$ & 0.937 \\
\hline Age(Y) & $39.08 \pm 6.18$ & $40.44 \pm 6.39$ & 0.620 \\
\hline BMI & $23.26 \pm 3.11$ & $23.95 \pm 2.30$ & 0.575 \\
\hline Follow-up time(T/M) & $65.6 \pm 3.20$ & $67.9 \pm 4.88$ & 0.201 \\
\hline Operation time(t/min) & $110.5 \pm 11.15$ & $134.44 \pm 12.36$ & $<0.01^{\mathrm{a}}$ \\
\hline Bleeding loss(V/ml) & $59.2 \pm 7.03$ & $80.0 \pm 8.66$ & $<0.01^{\mathrm{a}}$ \\
\hline PID(D/N) & $7 / 19$ & $4 / 14$ & 0.723 \\
\hline $\begin{array}{l}\text { a. K-rod group was different from PLIF group. PID(D/N): Preoperative imaging degeneration } \\
\text { (degeneration/no degeneration) }\end{array}$ & & \\
\hline
\end{tabular}

\section{Clinical efficacy}

In our study, we found that the incidence rates of intractable low-back pain and recurrence of neurological symptoms in K-rod group were higher than the incidence rates in PLIF group. The results were reflected by VAS score, ODI, and JOABPEQ. There was no significant difference in preoperative VAS score, ODI, and JOABPEQ between the two groups. However, at the last follow-up, VAS score $(2.1 \pm 0.9$ vs $3.0 \pm 0.7, P<$ $0.05)$ and $\mathrm{ODI}(21.0 \pm 3.7$ vs. $28.4 \pm 6.9, P<0.05)$ of patients in the K-rod group were significantly lower than those of patients in the PLIF group (Table 2). Conversely, we found higher JOABPEQ $(26.7 \pm 1.1$ vs. $25.2 \pm 1.5, P<0.05)$ in the K-rod group than in the PLIF group (Table 2). Fortunately, there was no recurrence of disc herniation in surgical segments or failure of internal fixation in both groups.

Table 2

Changes of clinical measures in both groups

\begin{tabular}{|lllllll|}
\hline & $\begin{array}{l}\text { K-rod group } \\
\text { PRO }\end{array}$ & $\begin{array}{l}\text { K-rod group } \\
\text { POL }\end{array}$ & $\begin{array}{l}\text { PLIF group } \\
\text { PRO }\end{array}$ & $\begin{array}{l}\text { PLIF group } \\
\text { POL }\end{array}$ & P1 value & P2 value \\
\hline VAS & $6.9 \pm 0.8$ & $2.1 \pm 0.9$ & $7.5 \pm 1.0$ & $3.0 \pm 0.7$ & 0.450 & $0.015^{\mathrm{a}}$ \\
\hline JOABPEQ & $13.4 \pm 1.5$ & $26.7 \pm 1.1$ & $13.2 \pm 1.7$ & $25.2 \pm 1.5$ & 0.836 & $0.003^{\mathrm{a}}$ \\
\hline ODI & $66.8 \pm 3.6$ & $21.0 \pm 3.7$ & $67.7 \pm 3.7$ & $28.4 \pm 6.9$ & 0.943 & $0.024^{\mathrm{a}}$ \\
\hline $\begin{array}{l}\text { a: } \text { K-rod group was different from PLIF group. } P 1 \text { value: } P \text { value of preoperative comparisons between } \\
\text { groups; } P 2 \text { value: } P \text { value of intergroup comparisons at the Last Follow-up; PRO: preoperation; POL: } \\
\text { the last follow-up after the operation }\end{array}$
\end{tabular}


There were no significant differences in adjacent segmental intervertebral height, ROM, spino-pelvic parameters, and LL between the two groups preoperatively.

At the last follow-up, the ROM of adjacent segments increased in both groups and was significantly higher in the PLIF group than in the K-rod group $(P<0.001)$. H decreased in both groups, but the decrease was significantly more in the PLIF group $(P<0.05)$. According to $>5$ years of follow-up data, the incidence of lumbar instability was $7.7 \%$ and $38.9 \%$, in the K-rod and PLIF groups, respectively. There were significant differences in the incidence of lumbar instability between the two groups $(P<0.05)$ (Table 3$)$.

Table 3

Changes of $\mathrm{H}$ and ROM data in both groups

\begin{tabular}{|c|c|c|c|c|c|c|}
\hline & $\begin{array}{l}\text { K-rod group } \\
\text { PRO }\end{array}$ & $\begin{array}{l}\text { K-rod group } \\
\text { POL }\end{array}$ & $\begin{array}{l}\text { PLIF group } \\
\text { PRO }\end{array}$ & $\begin{array}{l}\text { PLIF group } \\
\text { POL }\end{array}$ & $P 1$ value & $P 2$ value \\
\hline $\mathrm{H}_{(\mathrm{L} 3 / 4)}(\mathrm{mm})$ & $10.3 \pm 1.5$ & $10.0 \pm 1.4$ & $10.4 \pm 1.5$ & $8.9 \pm 1.9$ & 0.907 & 0.144 \\
\hline $\mathrm{H}_{(\mathrm{L} 5 / \mathrm{S} 1)}(\mathrm{mm})$ & $9.1 \pm 2.6$ & $8.8 \pm 2.9$ & $8.3 \pm 2.6$ & $6.7 \pm 2.7$ & 0.503 & 0.100 \\
\hline $\operatorname{ROM}_{(\mathrm{L} 3 / 4)}\left({ }^{\circ}\right)$ & $3.7 \pm 2.3$ & $4.9 \pm 2.0$ & $4.8 \pm 2.2$ & $8.8 \pm 2.4$ & 0.286 & $<0.001^{a}$ \\
\hline $\mathrm{ROM}_{\mathrm{L5/S} 1)}\left({ }^{\circ}\right)$ & $5.0 \pm 2.9$ & $5.7 \pm 1.7$ & $5.0 \pm 2.0$ & $8.6 \pm 1.2$ & 1.00 & $<0.001^{a}$ \\
\hline $\mathrm{HL}_{(\mathrm{L} / 4)}(\mathrm{mm})$ & - & $0.4 \pm 0.9$ & - & $1.5 \pm 0.7$ & - & $0.009^{a}$ \\
\hline $\mathrm{HL}_{(\mathrm{L} 5 / \mathrm{s} 1)}(\mathrm{mm})$ & - & $0.2 \pm 0.5$ & - & $1.8 \pm 1.7$ & - & $0.004^{a}$ \\
\hline ILI & - & $7.7 \%$ & - & $38.9 \%$ & - & $0.012^{\mathrm{a}}$ \\
\hline \multicolumn{7}{|c|}{$\begin{array}{l}\text { a: K-rod group was different from PLIF group. } P 1 \text { value: } P \text { value of preoperative comparisons between } \\
\text { groups; } P 2 \text { value: } P \text { value of intergroup comparisons at the Last Follow-up; PRO: preoperation; POL: } \\
\text { the last follow-up after the operation; HL: height of intervertebral space loss; ILI: incidence of lumbar } \\
\text { instability. }\end{array}$} \\
\hline
\end{tabular}

We found no significant difference in the PI value between the two groups before and after the surgery. There were no significant changes in PT, SS, and LL within the K-rod group before and after the operation. However, there were significant differences in the preoperative and postoperative values of these measures in patients in the PLIF group $(P<0.05)$. The overall trend was that SS and LL became smaller while PT became larger in the PLIF group (Table 4). 
Table 4

Changes of spinal-pelvis parameters in two groups

\begin{tabular}{|c|c|c|c|c|c|c|c|c|}
\hline & $\begin{array}{l}\text { K-rod } \\
\text { group PRO }\end{array}$ & $\begin{array}{l}\text { K-rod } \\
\text { group POL }\end{array}$ & $\begin{array}{l}\text { PLIF group } \\
\text { PRO }\end{array}$ & $\begin{array}{l}\text { PLIF group } \\
\text { POL }\end{array}$ & $\begin{array}{l}\mathrm{P} 1 \\
\text { value }\end{array}$ & $\begin{array}{l}\text { P2 } \\
\text { value }\end{array}$ & $\begin{array}{l}\text { P3 } \\
\text { value }\end{array}$ & $\begin{array}{l}\text { P4 } \\
\text { value }\end{array}$ \\
\hline $\mathrm{LL}\left({ }^{\circ}\right)$ & $32.2 \pm 18.0$ & $36.9 \pm 8.2$ & $49.3 \pm 8.7$ & $41.0 \pm 6.3$ & 0.748 & $0.002^{b}$ & 0.061 & $0.023^{a}$ \\
\hline $\mathrm{PT}\left({ }^{\circ}\right)$ & $17.3 \pm 9.0$ & $17.9 \pm 9.2$ & $23.0 \pm 8.2$ & $28.6 \pm 10.0$ & 0.826 & $0.005^{b}$ & 0.402 & $0.027^{a}$ \\
\hline $\operatorname{SS}\left({ }^{\circ}\right)$ & $28.0 \pm 9.6$ & $27.6 \pm 6.7$ & $33.4 \pm 8.9$ & $24.5 \pm 5.3$ & 0.889 & $0.002^{b}$ & 0.068 & $0.013^{a}$ \\
\hline $\mathrm{PI}\left({ }^{\circ}\right)$ & $45.4 \pm 11.2$ & $44.6 \pm 9.4$ & $56.0 \pm 11.0$ & $52.9 \pm 7.4$ & 0.338 & 0.301 & 0.057 & $0.004^{a}$ \\
\hline \multicolumn{9}{|c|}{$\begin{array}{l}\text { a. K-rod group was different from PLIF group; } \text { : PLIF group POL was different from PLIF group PRO; } \\
P 1 \text { value: } P \text { value of intra-group comparisons in K-rod group; } P 2 \text { value: } P \text { value of intra-group } \\
\text { comparisons in PLIF group. } P 3 \text { value: } P \text { Value of intergroup comparisons before the operation; } P 4 \\
\text { value: } P \text { value of intergroup comparisons at the last follow-up; PRO: preoperation; POL: the last follow- } \\
\text { up after the operation. }\end{array}$} \\
\hline
\end{tabular}

The results of the different grading methods used to evaluate postoperative ASD in the two groups are shown in Tables 5-7. The incidence of ASD was higher in the PLIF group than in the K-rod group (Table 8). Further analysis of the data showed that although different methods were used to evaluate ASD, the overall incidence of aggravation of ASD was the same as that established with Pfirrmann grading.

Table 5

Changes of UCLA grade before and after operation in two groups

\begin{tabular}{|lcccccccccc|}
\hline & \multicolumn{1}{c}{ UGCV(L3/4) } & \multicolumn{1}{c}{ UGCV(L5/S1) } \\
\cline { 2 - 11 } & $\mathbf{- 1}$ & $\mathbf{0}$ & $\mathbf{1}$ & $\mathbf{2}$ & $\mathbf{3}$ & $\mathbf{- 1}$ & $\mathbf{0}$ & $\mathbf{1}$ & $\mathbf{2}$ & $\mathbf{3}$ \\
\hline K-rod group & 0 & 12 & 1 & 0 & 0 & 0 & 13 & 0 & 0 & 0 \\
\hline PLIF group & 0 & 6 & 2 & 1 & 0 & 0 & 7 & 1 & 1 & 0 \\
\hline UGCV: UCLA grading change value = UCLA grading at the last follow-up - preoperative UCLA grading \\
\hline
\end{tabular}

Table 6

Changes of pfirrmann grade before and after operation in two groups

\begin{tabular}{|c|c|c|c|c|c|c|c|c|c|c|c|c|}
\hline & \multicolumn{6}{|c|}{ PGCV(L3/4) } & \multicolumn{6}{|c|}{ PGCV(L5/S1) } \\
\hline & -1 & 0 & 1 & 2 & 3 & 4 & -1 & 0 & 1 & 2 & 3 & 4 \\
\hline K-rod group & 0 & 11 & 2 & 0 & 0 & 0 & 1 & 11 & 1 & 0 & 0 & 0 \\
\hline PLIF group & 0 & 4 & 2 & 2 & 1 & 0 & 0 & 4 & 3 & 2 & 0 & 0 \\
\hline
\end{tabular}


Table 7

Changes of MODIC grade before and after operation in two groups

\begin{tabular}{|lccccccccccc}
\hline & \multicolumn{1}{c}{ MGCV(L3/4) } & \multicolumn{1}{c}{ MGCV(L5/S1) } \\
\cline { 2 - 11 } & $\mathbf{- 1}$ & $\mathbf{0}$ & $\mathbf{1}$ & $\mathbf{2}$ & $\mathbf{3}$ & $\mathbf{- 1}$ & $\mathbf{0}$ & $\mathbf{1}$ & $\mathbf{2}$ & $\mathbf{3}$ \\
\hline K-rod group & 0 & 13 & 0 & 0 & 0 & 0 & 12 & 1 & 0 & 0 \\
\hline PLIF group & 0 & 7 & 2 & 0 & 0 & 0 & 7 & 1 & 1 & 0
\end{tabular}

MGCV: MODIC grading change value = MODIC grading at the last follow-up - preoperative MODIC grading

Table 8

Postoperative degeneration rate in K-rod group and PLIF group

\begin{tabular}{|llll|}
\hline & K-rod group & PLIF group & P value \\
\hline Pfirrmann grade & $15.4 \%$ & $55.6 \%$ & 0.005 \\
\hline MODIC grade & $3.8 \%$ & $22.2 \%$ & 0.059 \\
\hline UCLA grade & $3.8 \%$ & $27.8 \%$ & $0.023^{\mathrm{a}}$ \\
\hline ROHL & $3.8 \%$ & $16.7 \%$ & 0.146 \\
\hline $\begin{array}{l}\text { a. } \text { K-rod group was different from PLIF group. ROHL: The rate of intervertebral height loss(more than } \\
20 \%)\end{array}$ & & \\
\hline
\end{tabular}

\section{Discussion}

This study compared the clinical outcomes of K-rod-assisted non-fusion surgery and PLIF for the treatment of single-segment lumbar disc herniation. According to the literature report ${ }^{16,17}$ and the accumulated clinical experience of our team, it is believed that the use of a dynamic stabilization internal fixation system to treat lumbar disc herniation needs to exclude spinal instability and severe osteoporosis. In addition, we know little about the long-term clinical effects of the dynamic stabilization system in the treatment of lumbar disc herniation, and it requires a lifetime of continuous movement. In order to avoid some unpredictable potential risks, we excluded patients over 55 years of age when providing the treatment option of K-rod-assisted surgery to patients. Similarly, in order to ensure the homogeneity of the study, the patients included in the PLIF group were also less than 55 years old.

This study demonstrated that operative time and blood loss in the K-rod group were significantly lower than those in the PLIF group. This is because K-rod surgical procedure was simpler than the PLIF procedure, and this is an advantage of K-rod surgery over PLIF. After comparing follow-up results, we also found better clinical efficacy in the K-rod group. This improvement in clinical efficacy is closely related to spinal sagittal balance and ASD after spinal surgery. ${ }^{18}$ Intractable low-back pain is a common complication after lumbar spinal surgery, and in severe cases, reoperation is required. ${ }^{19}$ Previous studies 
have shown that the incidence of low-back pain after lumbar discectomy is $5-36 \% .{ }^{20}$ Multiple factors are responsible for postoperative low-back pain, and lumbar instability plays an important role. ${ }^{21}$ Each vertebral body and its adjacent intervertebral disc tissue constitute a motion unit. After lumbar fusion surgery, the motion unit of the operated segment changes and its activity increases completely, requiring compensation from the adjacent motion unit, thus changing the stress of the adjacent intervertebral disc tissue and facet joints. Over time, instability and degeneration of the spine occur. In this study, $38.9 \%$ of PLIF patients were found to have lumbar instability after 5 years of follow-up. However, it is worth noting that although the ROM of adjacent segments did not exceed $10^{\circ}$ in the K-rod group, the activity of the upper segments increased significantly, and was significantly different between the two groups. This suggests that the K-rod system retains the activity of the operative segments, but there may still be compensatory movement during flexion and extension after surgery. This may also be due to the age of the patient, ${ }^{22}$ because age-related disc degeneration was found to coexist in these patients.

$\mathrm{H}$ indirectly reflects the height of the intervertebral disc. ${ }^{23}$ Lu et al. ${ }^{24}$ found that a decrease in the height of the intervertebral disc caused the following changes: the stress in the center of the disc decreased, the stress in the peripheral fibrous ring increased, the risk of rupture of the fibrous ring increased, and the stress in the facet process increased. All these changes accelerated the degeneration of adjacent segments. Our long-term clinical observations in this study confirmed that $\mathrm{H}$ decreased in adjacent segments after posterior lumbar fusion (Table 3). Similar results were not found in the K-rod group because the elastic rod not only partially retained the flexion and extension motion of the lumbar spine, but also had a much lower modulus of elasticity and a weaker stress-shielding effect than the rigid rod.

It is also important to note that before intervertebral space changes become obvious, disc degeneration will have become visible on MRI. According to Pfirrmann grading, ${ }^{25}$ disc height loss is detectable only when disc degeneration reaches grade IV or above. Modic changes refer to the expression of bone changes in the endplate and sub-endplate on MRI. Two main mechanisms are responsible for Modic changes. First, the mechanical properties of the endplate are changed by disc degeneration and microfractures occur under repeated loads. Second, inflammatory substances released by the degenerated disc stimulate the endplate. Disruption of the endplate results in impairment of nutrient transport that further accelerates disc degeneration. ${ }^{26,27}$ Therefore, these two mechanisms complement each other in the process of lumbar degeneration. All cases with Modic changes in this study were associated with disc degeneration corresponding to a Pfirrmann grade of at least III. In general, Modic type I and type II changes are reversible, ${ }^{28}$ and the spinal segment involved could return to normal. In our study, the incidence of Modic changes was 3.8\% in the K-rod group and 22.2\% in the PLIF group, suggesting that when adjacent segments have mild Modic changes without symptoms of lumbar disc herniation and nerve compression, non-fusion and internal fixation with K-rod system may be more beneficial, and complications associated with premature fusion can be avoided.

Pelvic morphology also plays an important role in the sagittal balance of the spine..$^{29,30}$ Currently, evaluation of the morphology of the pelvis mainly involves three parameters: PI, PT, and SS. There is a 
clear geometric relationship between these three parameters, which is expressed as $\mathrm{PI}=\mathrm{PT}+\mathrm{SS}$. Furthermore, Schwab also found an equation for spine and pelvis parameters in asymptomatic patients: $L L=P I \pm 9^{\circ} .{ }^{31}$ When degenerative changes occur in the lumbar spine, these parameters change; for instance, the PI value will increase in patients with degenerative lumbar spondylolisthesis. ${ }^{30,32-34}$ Meanwhile, surgery affects spino-pelvic parameters as well as LL. ${ }^{35-38}$ We found no significant differences in the PI value between the PLIF group and K-rod group before or after operation. However, in the last follow-up, we noticed an increase in PT and a decrease in both SS and LL in patients in the PLIF group. This suggests that spine instability still existed at the last follow-up after lumbar surgery.

Our study shows the K-rod system-assisted elastic internal fixation for lumbar disc herniation has superior medium- to long-term clinical efficacy when compared to PLIF. However, there are several limitations to this study. First, the number of cases involved was small, as the sample size was only 22 cases. Second, the treatment of lumbar disc herniation with the K-rod elastic internal fixation system usually uses the routine posterior spinal approach. This can cause serious muscle damage and may also cause postoperative low-back pain. These problems may have improved if the interstitial approach was used. In addition, the K-rod system, which belongs to the posterior spinal screw-rod system, is no longer removed after implantation unless necessitated by special conditions. As patients grow older, screw loosening and screw-rod electrolysis may occur. Moreover, the elastic rod can cause partial motion of the operative segment and, thus, increase the risk of failure of the spinal screw-rod system. Although in the 5year follow-up period of this study, there was no reported case of internal fixation failure, the risk of this complication is not clear, and further studies are needed.

In conclusion, the K-rod system-assisted elastic internal fixation when used for the treatment of lumbar intervertebral disc herniation in young and middle-aged individuals can achieve greater clinical efficacy than PLIF. It can also reduce the associated pain, resolve functional disorders, and ensure spinal stability and spinal balance for the patient. It has the advantages of minimal trauma, a shorter operative time, minimal blood loss, and a faster recovery period postoperatively compared to PLIF. The K-rod system also retains the normal activities of the operative segment and limits abnormal activities. The present study shows that the K-rod system has the effect of delaying ASD after lumbar surgery from various angles. Currently, the indications for using the K-rod system in the management of lumbar degenerative diseases are not clear. We intend to further evaluate the clinical efficacy and related complications of the K-rod system in the management of lumbar degenerative diseases in order to provide a basis for establishing an optimal treatment method.

\section{Declarations}

Ethics approval and consent to participate: This study complied with the Declaration of Helsinki and was reviewed and approved by the Ethics Committee of the Second Hospital of Jilin University. All patients in our study provided informed consent.

Consent for publication: Written informed consent for publication was obtained from all participants. 
Availability of data and materials: Not applicable.

Competing interests: We declare that we have no competing interests.

Funding: This work was supported by Jilin Provincial Science and Technology Agency (NO. 20170204031YY) and Graduate Innovation Fund of Jilin University (NO. 101832020CX295).

Authors' contributions: Xue-liang Cheng designed and performed the research and wrote the paper; Yang Qu designed the research and provided clinical advice; Rong-peng Dong designed the research and contributed to the analysis; Ming-yang Kang collected the information and provided clinical advice; Jianwu Zhao guided the research and supervised the report.

Acknowledgment: Not applicable.

\section{References}

1 Hashimoto K, Aizawa T, Kanno H, Itoi E. Adjacent segment degeneration after fusion spinal surgery-a systematic review. Int Orthop 2019;43:987-993 [PMID: 30470865 DOI: 10.1007/s00264-018-4241-z]

2 Yijian Z, Hao L, Huilin Y, Bin P. Comparison of posterolateral fusion and posterior lumbar interbody fusion for treatment of degenerative spondylolisthesis: Analysis of spino-pelvic sagittal balance and postoperative chronic low back pain. Clin Neurol Neurosurg. 2018;171:1-5 [PMID囚 29800807 DOI区 10.1016 / j.clineuro.2018.04.020]

3 Hilibrand AS, Robbins M. Adjacent segment degeneration and adjacent segment disease: the consequences of spinal fusion? Spine J 2004; 4 Suppl 6:190S-194S [PMID: 15541666 DOI:

10.1016/j.spinee.2004.07.007]

4 Lee CK. Accelerated degeneration of the segment adjacent to a lumbar fusion. Spine (Phila Pa 1976) 1988;13:375-377 [PMID: 3388124 DOI: 10.1097/00007632-198803000-00029]

5 Park P, Garton HJ, Gala VC, Hoff JT, McGillicuddy JE. Adjacent segment disease after lumbar or lumbosacral fusion: review of the literature. Spine (Phila Pa 1976) 2004;29:1938-1944 [PMID: 15534420 DOI: 10.1097/01.brs.0000137069.88904.03]

6 Cheh G, Bridwell KH, Lenke LG, Buchowski JM, Daubs MD, Kim Y, Baldus C. Adjacent segment disease following lumbar/thoracolumbar fusion with pedicle screw instrumentation: a minimum 5-year follow-up. Spine (Phila Pa 1976) 2007; 32:2253-2257 [PMID: 17873819 DOI: 10.1097/BRS.0b013e31814b2d8e]

7 Imagama S, Kawakami N, Matsubara Y, Tsuji T, Ohara T, Katayama Y, Ishiguro N, Kanemura T. Radiographic adjacent segment degeneration at 5 years after $L 4 / 5$ posterior lumbar Interbody fusion with pedicle screw instrumentation: evaluation by computed tomography and annual screening with magnetic resonance imaging. Clin Spine Surg 2016; 29:e442-e451 [PMID: 27755201 DOI:

10.1097/BSD.0b013e31828aec78]

Page $12 / 17$ 
8 Iorio JA, Jakoi AM, Singla A. Biomechanics of Degenerative Spinal Disorders. Asian Spine J 2016;10:377-384 [PMID: 27114783 DOI: 10.4184/asj.2016.10.2.377]

9 Sengupta DK, Herkowitz HN. Pedicle screw-based posterior dynamic stabilization: literature review. Adv Orthop 2012;424268 [PMID: 23227349 DOI: 10.1155/2012/424268]

10 Pan A, Hai Y, Yang J, Zhou L, Chen X, Guo H. Adjacent segment degeneration after lumbar spinal fusion compared with motion-preservation procedures: a meta-analysis. Eur Spine J 2016;25:1522-1532

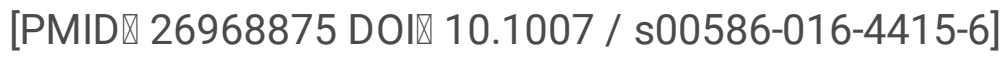

11 Donnally CJ, Patel PD, Canseco JA, Divi SN, Goz V, Sherman MB, Shenoy K, Markowitz M, Rihn JA, Vaccaro AR. Current incidence of adjacent segment pathology following lumbar fusion versus motionpreserving procedures: a systematic review and meta-analysis of recent projections. Spine J 2020;20:S1529-9430(20)30291-6 [PMID: 32445805 DOI: 10.1016/j.spinee.2020.05.100]

12 Qu Y, Cheng M, Dong R, Kang M, Zhou H, Zhao J. K-rod dynamic internal fixation versus microendoscopic discectomy for the treatment of single-segment lumbar disc herniation. J Orthop Surg (Hong Kong) 2017;25:2309499017742740 [PMID: 29212437 DOI: 10.1177/2309499017742740]

13 Wang H, Lv B. Comparison of clinical and radiographic results between posterior pedicle-based dynamic stabilization and posterior lumbar intervertebral fusion for lumbar degenerative disease: a 2-Year retrospective study. World neurosurg 2018;114:e403-e411 [ PMID: 29530683 DOI: 10.1016/j.wneu.2018.02.192]

14 Han Y, Sun J, Luo C, Huang S, Li L, Ji X, Duan X, Wang Z, Pi G. Comparison of pedicle screw-based dynamic stabilization and fusion surgery in the treatment of radiographic adjacent-segment degeneration: a retrospective analysis of single L5-S1 degenerative spondylosis covering 4 years. $J$ Neurosurg Spine 2016;25:706-712 [PMID: 27341057 DOI: 10.3171/2016.4.SPINE1679]

15 Kim JY, Ryu DS, Paik HK, Ahn SS, Kang MS, Kim KH, Park JY, Chin DK, Kim KS, Cho YE, Kuh SU. Paraspinal muscle, facet joint, and disc problems: risk factors for adjacent segment degeneration after lumbar fusion. Spine J 2016;16:867-75 [PMID: 26970600 doi: 10.1016/j.spinee.2016.03.010. Epub 2016 Mar 9]

16 Kuo YH, Kuo CH, Chang HK, Tu TH, Fay LY, Chang CC, Cheng H, Wu CL, Lirng JF, Wu JC, Huang WC. Effects of smoking on pedicle screw-based dynamic stabilization: radiological and clinical evaluations of screw loosening in 306 patients. J Neurosurg Spine 2020, 1:1-8 [PMID: 32357328 DOI: 10.3171/2020.2.SPINE191380. Epub ahead of print]

17 Wu JC, Huang WC, Tsai HW, Ko CC, Wu CL, Tu TH, Cheng H. Pedicle screw loosening in dynamic stabilization: incidence, risk, and outcome in 126 patients. Neurosurg Focus 2011;31:E9 [PMID: 21961872 DOI: 10.3171/2011.7.FOCUS11125] 
18 Benzakour T, Benzakour A. Disc herniation and disc disease: the present and the future of management. Int Orthop. 2019;43(4):7555-760 [PMID: 30891636 DOI: 10.1007/s00264-019-04324-y]

19 Kim CH, Chung CK, Park CS, Choi B, Kim MJ, Park BJ. Reoperation rate after surgery for lumbar herniated intervertebral disc disease: nationwide cohort study. Spine (Phila Pa 1976) 2013;38:581-590.

20 Iguchi T, Kanemura A, Kasahara K, Sato K, Kurihara A, Yoshiya S, Nishida K, Miyamoto H, Doita M. Lumbar instability and clinical symptoms: which is the more critical factor for symptoms: sagittal translation or segment angulation? J Spinal Disord Tech 2004;17:284-290 [PMID: 15280756 DOI: 10.1097/01.bsd.0000102473.95064.9d]

21 Parker SL, Mendenhall SK, Godil SS, Sivasubramanian P, Cahill K, Ziewacz J, McGirt MJ. Incidence of low back pain after lumbar discectomy for herniated disc and its effect on patient-reported outcomes. Clin Orthop Relat Res 2015;473:1988-1999 [PMID: 25694267 PMCID: PMC4419014 DOI: 10.1007/s11999-015-4193-1]

22 Khan JM, Basques BA, Harada GK, Louie PK, Chen I, Vetter C, Kadakia K, Elboghdady I, Colman M, An HS. Does increasing age impact clinical and radiographic outcomes following lumbar spinal fusion?. Spine J 2020;20:563-571 [PMID: 31731010 DOI: 10.1016/j.spinee.2019.11.003]

23 Berlemann U, Gries NC, Moore RJ. The relationship between height, shape and histological changes in early degeneration of the lower lumbar discs. Eur Spine J 1998;7:212-217 [PMID: 9684954 DOI:

$10.1007 / \mathrm{s} 005860050058]$

24 Lu YM, Hutton WC, Gharpuray VM. Can variations in intervertebral disc height affect the mechanical function of the disc?. Spine (Phila Pa 1976) 1996;21:2208-2217 [PMID: 8902964 DOI:

10.1097/00007632-199610010-00006]

25 Rade M, Määttä JH, Freidin MB, Airaksinen O, Karppinen J, Williams FMK. Vertebral endplate defect as initiating factor in intervertebral disc gegeneration: strong association between endplate defect and disc degeneration in the general population. Spine (Phila Pa 1976) 2018;43:412-419 [PMID: 28749857 PMCID: PMC5756623 DOI: 10.1097/BRS.0000000000002352]

26 Cho BY, Murovic J, Park KW, Park J. Lumbar disc rehydration postimplantation of a posterior dynamic stabilization system. J Neurosurg Spine 2010;13:576-580 [PMID: 21039146 DOI:

10.3171/2010.5.SPINE08418]

27 Grignon B, Grignon Y, Mainard D, Braun M, Netter P, Roland J. The structure of the cartilaginous endplates in elder people. Surg Radiol Anat 2000;22:13-19 [PMID: 10863741 DOI: 10.1007/s00276-000-00137]

28 Dudli S, Fields AJ, Samartzis D, Karppinen J, Lotz JC. Pathobiology of Modic changes. Eur Spine J 2016;25:3723-3734 [PMID: 26914098 DOI: 10.1007/s00586-016-4459-7] 
29 Shah AA, Lemans JV, Zavatsky J, Agarwal A, Kruyt MC, Matsumoto K, Serhan H, Agarwal AK, Goel V. Spinal balance/alignment - clinical relevance and biomechanics. J Biomech Eng 2019;141:14 [PMID: 31049580 DOI: 10.1115/1.4043650]

30 Le Huec JC, Thompson W, Mohsinaly Y, Barrey C, Faundez A. Sagittal balance of the spine. Eur Spine J 2019;28:1889-1905 [PMID: 31332569 DOI: 10.1007/s00586-019-06083-1]

31 Schwab F, Lafage V, Patel A, Farcy JP. Sagittal plane considerations and the pelvis in the adult patient. Spine (Phila Pa 1976) 2009;34:1828-1833 [ PMID: 19644334 DOI: 10.1097/BRS.0b013e3181a13c08]

32 Funao H, Tsuji T, Hosogane N, Watanabe K, Ishii K, Nakamura M, Chiba K, Toyama Y, Matsumoto M. Comparative study of spinopelvic sagittal alignment between patients with and without degenerative spondylolisthesis. Eur Spine J 2012;21:2181-2187 [PMID: 22639298 DOI: 10.1007/s00586-012-2374-0]

33 Jackson RP, Phipps T, Hales C, Surber J. Pelvic lordosis and alignment in spondylolisthesis. Spine (Phila Pa 1976) 2003;28:151-160 [PMID: 12544932 DOI: 10.1097/00007632-200301150-00011]

34 Borkar SA, Sharma R, Mansoori N, Sinha S, Kale SS. Spinopelvic parameters in patients with lumbar degenerative disc disease, spondylolisthesis, and failed back syndrome: Comparison vis-à-vis normal asymptomatic population and treatment implications. J Craniovertebr Junction Spine 2019;10:167-171 [PMID: 31772429 DOI: 10.4103/jcvjs.JCVJS_70_19]

35 Potter BK, Lenke LG, Kuklo TR. Prevention and management of iatrogenic flatback deformity. J Bone Joint Surg Am 2004;86:1793-1808 [PMID: 15292431 DOI: 10.2106/00004623-200408000-00027]

36 Sarwahi V, Boachie-Adjei O, Backus SI, Taira G. Characterization of gait function in patients with postsurgical sagittal (flatback) deformity: a prospective study of 21 patients. Spine (Phila Pa 1976) 2002;27:2328-2337 [PMID: 12438980 DOI: 10.1097/00007632-200211010-00005]

37 Anand N, Alayan A, Agrawal A, Kahwaty S, Nomoto E, Khandehroo B. Analysis of Spino-Pelvic Parameters and Segmental Lordosis with L5-S1 Oblique Lateral Interbody Fusion at the Bottom of a Long Construct in Circumferential Minimally Invasive Surgical Correction of Adult Spinal Deformity. World Neurosurg 2019;130:e1077-e1083 [PMID: 31323412 DOI: 10.1016/j.wneu.2019.07.091]

38 Alqroom R. The quest of sagittal balance parameters and clinical outcome after short segment spinal fusion. Acta Inform Med 2018;26:57-61 [PMID: 29719316 DOI: 10.5455/aim.2018.26.57-61]

\section{Figures}




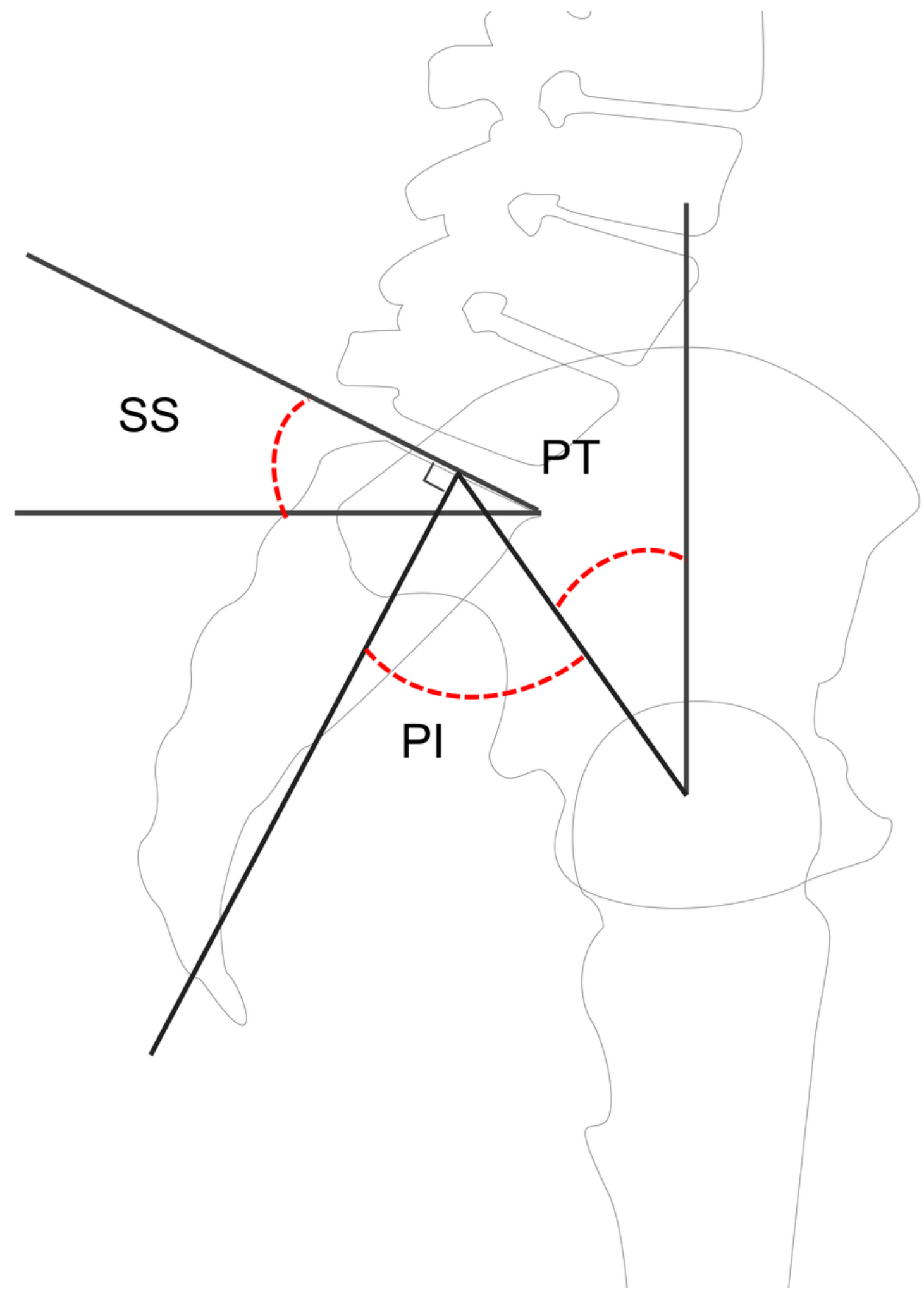

\section{Figure 1}

The method for measuring height of intervertebral space $H=(h 1+h 2+h 3+h 4) / 2$. Line $A$ is the line connecting the midpoint of $a$ and $d$ and the midpoint of $b$ and $c$. Line $B$ is the bisector of the two lines $A$. $h 1, h 2, h 3$, and h4 represent the distances from the point d/c to line B. 


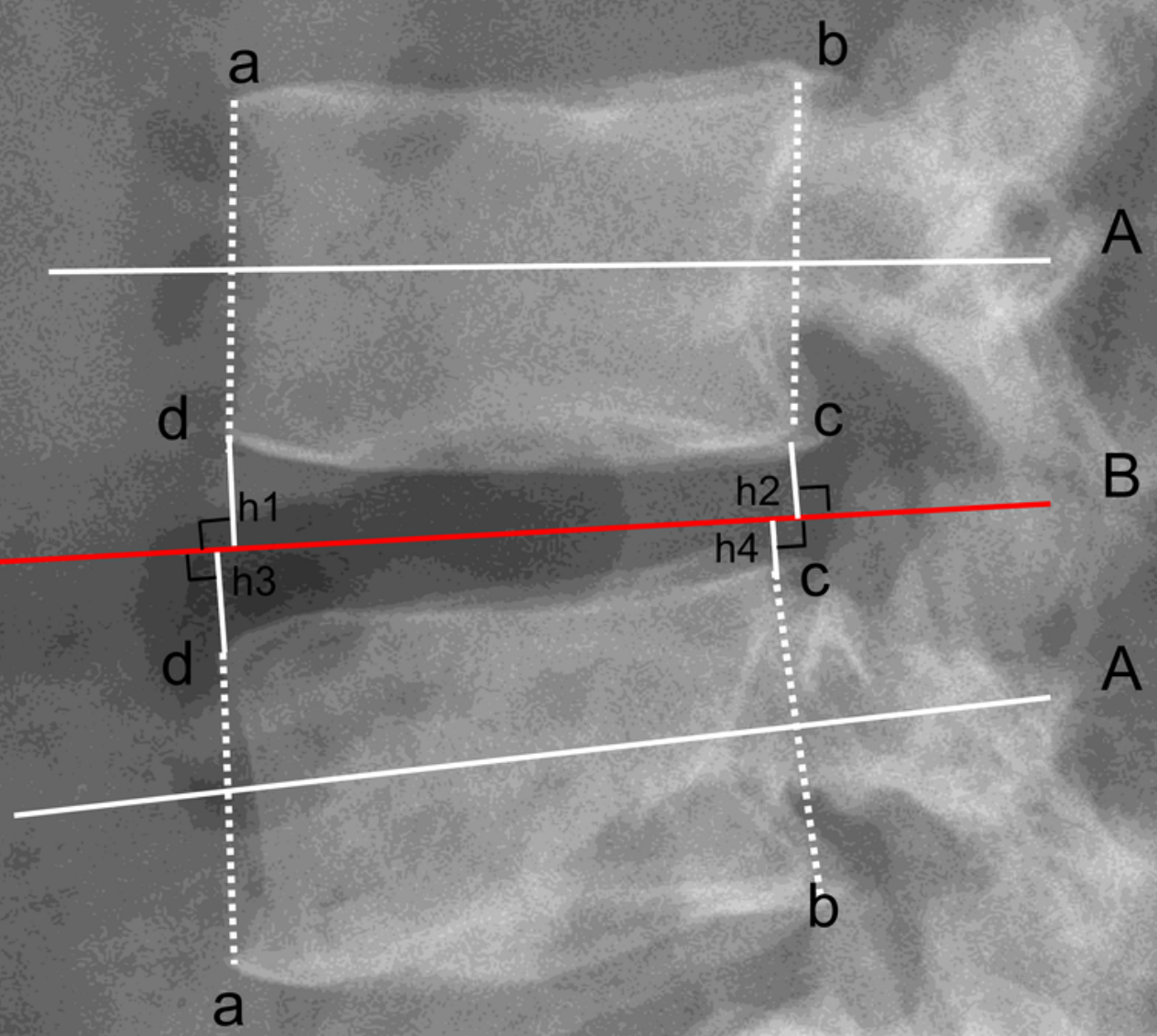

\section{Figure 2}

The methods for measuring pelvic parameters SS is the angle between the horizontal line and the parallel line of the sacral endplate; PI is the angle between the vertical line of the midpoint of the sacrum and the line connecting the midpoint of the sacrum and the center of the femoral head; PT is the angle between the vertical line and the line connecting the midpoint of the sacrum and the center of the femoral head. 